\title{
Epidemiology of intraocular pressure in a population screened for glaucoma*
}

\author{
ROBERT DAVID,' LINDA ZANGWILL,' DAVID STONE, ${ }^{2}$ \\ AND YUVAL YASSUR' \\ From the 'Middle East Eye Research Institute, Department of Ophthalmology, and 'Department of \\ Epidemiology, Faculty of Health Sciences, Ben Gurion University of the Negev, Beer Sheva, Israel
}

SUMMARY This study evaluated the association between intraocular pressure and various sociodemographic characteristics, ocular findings, and cardiovascular risk factors in a population screened for glaucoma. A total of 2594 subjects older than 40 years residing in three urban areas of southern Israel participated. Of those screened $6 \cdot 1 \%$ had a raised intraocular pressure (IOP $\geqslant 21$ ). The mean IOP increased with age, was higher among persons born in Africa or Asia than those born in Europe or America, higher among myopes than hypermetropes and among those with an enlarged cup-disc ratio (CDR). Analysis of variance tests indicated that refractive status, CDR, age, country of birth, and diabetes were each independently associated with IOP. In addition, associations between raised intraocular pressure and age, country of birth, myopia, CDR, diabetes, and glaucoma in the family were found.

A raised intraocular pressure is a major ophthalmologic risk factor for the development of glaucomatous visual field defects. The prevalence of ocular hypertension is estimated to be between 5 and $10 \% .^{1-4}$ Unfortunately the aetiology of this condition and its relationship to glaucoma is not well understood.

This study uses data from the glaucoma screening of a population in southern Israel to investigate the epidemiology of intraocular pressure. Its objectives were to estimate the prevalence of ocular hypertension in the general population and to analyse the relationship of intraocular pressure to various sociodemographic characteristics, ocular findings, and systemic risk factors.

\section{Material and methods}

A population screening examination for glaucoma performed between 1982 and 1984 in three urban areas in southern Israel was the source of information for this study. Details of the screening protocol have been published elsewhere. ${ }^{5}$

There were two parts to the examination-an interview and an eye examination-performed at

\footnotetext{
* This paper was presented in part at the Second NEI Symposium on Eye Disease Epidemiology, June 1985.

Correspondence to Dr R David.
}

two stations. On arrival each subject was interviewed by a medical student and the following data were recorded: year of birth, sex, country of birth, systemic illness (diabetes, hypertension requiring current medication, other cardiovascular conditions, and 'other'), history of haemodynamic shock, family history of glaucoma, and description of life style with regard to physical activity. Subjects reporting occasional hypertension, or not receiving medication for it, were not considered as hypertensives for this survey. A subject was considered diabetic if he or she was on a diabetic diet with or without additional regular medications. Cardiovascular conditions (other than hypertension) were heart or peripheral vascular diseases as documented by current medication and/or past admissions to hospital. As to life style, four categories of physical activity were defined as follows: sedentary (e.g., sedentary occupation, no regular physical activity), sedentary with occasional mild physical activity, medium physical activity, and marked physical activity (e.g., strenuous job or housewife, climbs stairs to apartment, etc.). Past haemodynamic shock was recorded when a subject recalled a major operation, accident, or other occasion necessitating blood transfusions.

The eye examinations were carried out by ophthalmologists with at least three years' experience. The parameters recorded were: 
Intraocular pressure (IOP). This was measured with the Goldmann applanation tonometer on either the Haag-Streit 900 or Topcon LD2 slit-lamp. The average of three consecutive readings was recorded for each eye. For the purposes of analysis, ocular hypertension was defined as an IOP greater than or equal to $21 \mathrm{mmHg}$ in at least one eye.

Optic disc assessment. The optic disc of every eye was examined with the direct ophthalmoscope and, whenever possible, through a non-dilated pupil. The cup-disc ratio (CDR) was judged by contour (and not by colour). Three categories of CDR were recorded $(\mathrm{CDR} \leqslant 0.3, \mathrm{CDR}>0.3$ and $\leqslant 0.5$, and $C D R>0.5)$ for both the horizontal and vertical meridian.

Refractive status. Determination of refractive status was made according to the subject's distance spectacles and recorded as emmetrope $(+2.00$ to -2.00 dioptres), hypermetrope $(+2.25$ dioptres or more), myope ( $-2 \cdot 25$ to $-5 \cdot 00$ dioptres), and high myopes (more than -5.00 dioptres). The glasses were tested with a lensometer by an ophthalmic nurse or optometrist.

The $\chi^{2}$ test, analysis of variance, and $t$ test methods were used to assess statistical significance.

\section{RESPONSE RATE}

Of the 4993 who received invitations 2594 (53\%) responded. A survey of a sample of the nonrespondents was conducted, the results of which are reported elsewhere. ${ }^{5}$ In short, a comparison of sociodemographic characteristics of respondents with non-respondents indicated that there was no significant difference in the composition of the two groups in terms of sex or country of birth. However, the respondents were younger than the non-respondents $\left(\chi^{2}\right.$ test, $\left.\mathrm{p}<0.001\right)$. The respondents had a smaller proportion of persons over 70 years of age than nonrespondents ( $12 \cdot 1 \%$ versus $19.2 \%$ respectively). In a similar manner the respondents had a larger proportion of persons between the ages of 40 and $49(38 \cdot 1 \%$ versus $36.7 \%)$ and between the ages of 50 and 59 $(30.5 \%$ versus $25 \cdot 3 \%)$ than non-respondents.

\section{Results}

The intraocular pressure was measured in 2547 people (5068 eyes). One hundred and fifty five of the persons with IOP measurements available were found to be ocular hypertensives $(21 \mathrm{mmHg}$ or more in at least one eye). The prevalence of ocular hypertension in the screened population was therefore $6 \cdot 1 \%$.

The mean and standard deviation of the IOP of the right eye was $14.96, \mathrm{SD} 4 \cdot 24, \mathrm{mmHg}$, of the left $14 \cdot 86, \mathrm{SD} 4.03, \mathrm{mmHg}$. The median for both eyes was $14 \mathrm{mmHg}$.
The mean IOP by age is presented in Table 1 . The mean IOP was found to increase incrementally by age from $14.35 \mathrm{mmHg}$ among subjects under 50 years old to $15.49 \mathrm{mmHg}$ among those over 70 years. This difference in means was statistically significant $(p<0.001)$ as determined by a one-way analysis of variance.

There was no difference in mean IOP between males and females. The mean and standard deviation of the IOP of the right eye for males was $15 \cdot 00$, SD $4.51, \mathrm{mmHg}$ and for females $14.94, \mathrm{SD} 3.99, \mathrm{mmHg}$. The mean IOP was found to be significantly higher ( $t$ test, $p \leqslant 0.001$ ) among persons of North African or Asian birth than persons of European or American birth, 15.39, SD 4.42, and 14.53, SD 3.64, respectively. These results are presented in Table 2 .

The age adjusted distribution of subjects by sex and country of birth was found to be significantly different $(p<0.01)$ among persons with raised IOP than normotensives. $9.8 \%$ of the 556 men and $7.5 \%$ of the 649 women born in Asia or Africa were found to have an IOP $>20$, whereas only $4.6 \%$ of the 691 women and $6.1 \%$ of the 659 men born in Europe or America had a raised IOP. These results are presented in Fig. 1 and Table 3.

The age distribution of persons with raised IOP was also significantly different $\left(\chi^{2}\right.$ test, $\left.p<0.001\right)$ from that of normotensives. While over $9 \%$ of persons aged 70 years and above $(n=365)$ had a raised IOP, only $3.2 \%$ of persons under 50 years of age $(n=878), 6 \cdot 0 \%$ of persons $50-59$ years $(n=780)$ and $8.4 \%$ of persons between the ages of 60 and 69 $(n=571)$ had such elevation. These results are presented in Fig. 2 and Table 4.

INTRAOCULAR PRESSURE AND CUP-DISC RATIO The four recorded CDR measurements, right hori-

Table 1 Mean IOP by age (right eye)

\begin{tabular}{lccll}
\hline Age (years) & $n$ & $\%$ & Mean IOP & $S D$ \\
\hline $40-49$ & 862 & 34 & $14 \cdot 35$ & $3 \cdot 07$ \\
$50-59$ & 760 & 30 & $15 \cdot 13$ & $4 \cdot 72$ \\
$60-69$ & 554 & 22 & $15 \cdot 35$ & 3.94 \\
$70+$ & 357 & 14 & $15 \cdot 49$ & $5 \cdot 67$ \\
Total & 2533 & 100 & $14 \cdot 96$ & $4 \cdot 24$ \\
\hline
\end{tabular}

( $F=9.84$, significance of $F<0.001)$.

Table 2 Mean IOP by country of birth (right eye)

\begin{tabular}{llrll}
\hline Country of birth & $n$ & $\%$ & Mean IOP & SD \\
\hline American or European & 1338 & 54 & 14.53 & 3.64 \\
Asian or African & 1166 & 46 & 15.39 & 4.42 \\
Total & 2504 & 100 & 14.93 & 4.04 \\
\hline
\end{tabular}

$t=5 \cdot 33, \mathrm{p}<0 \cdot 001$. 
Fig. 1 Age adjusted distribution of ocular hypertension by sex and country of birth. $x$ axis: sex and country of birth. y axis: percentage with ocular hypertension. Solid: percentage with ocular hypertension.
$Y$ axis: Percent with Ocular Hypertension

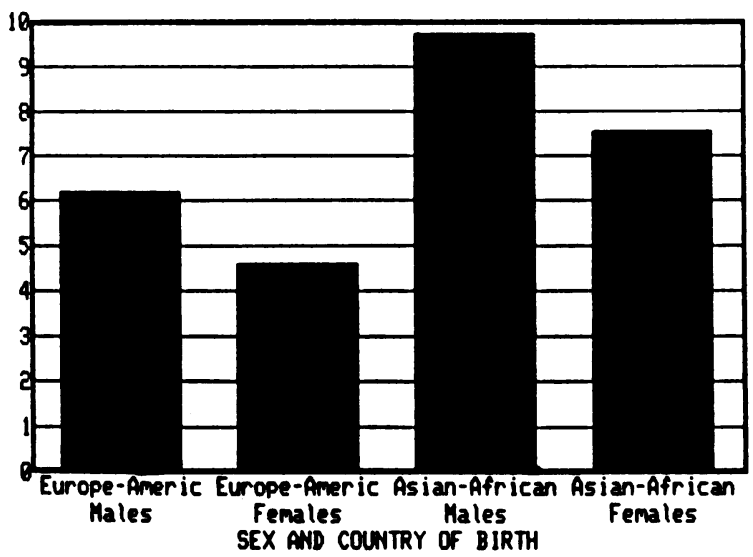

Table 3 Age adjusted distribution of ocular hypertension by sex and country of birth

\begin{tabular}{llll}
\hline Sex & Country of birth & $\begin{array}{l}\text { Percentage ocular } \\
\text { hypertension }\end{array}$ & $n$ \\
\hline Male & American and European & $6 \cdot 1$ & 659 \\
Male & Asian and African & $9 \cdot 6$ & 556 \\
Female & American and European & $4 \cdot 6$ & 491 \\
Female & Asian and African & $7 \cdot 5$ & 649 \\
\hline
\end{tabular}

Table 4 Agedistribution of ocular hypertensives

\begin{tabular}{lll}
\hline Age $(y r)$ & Percentage ocular hypertension & $n$ \\
\hline Less than 50 & $3 \cdot 2$ & 878 \\
50 to 59 & $6 \cdot 0$ & 780 \\
60 to 69 & $8 \cdot 4$ & 571 \\
70 to 79 & $9 \cdot 5$ & 365 \\
\hline
\end{tabular}

$Y$ axis: Percent with Elevated IUP

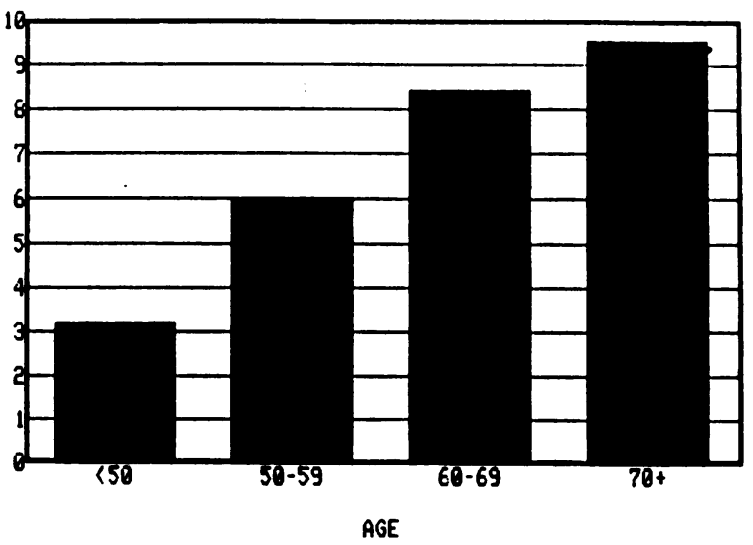

(ANOVA: $F=9.84$, Significance of $F<.001$ ) with ocular hypertension.

Fig. 2 Raised intraocular pressure by age $x$ axis: age y axis:

$10 P>20$ $N=155$ percentage with ocular hypertension. Solid: percentage

$10 P>28 n=153$

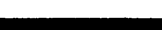
right eye, and CDR of the left eye as follows: $>0.50$ in at least one meridian, between 0.3 and 0.5 but no higher in at least one meridian, and $<0.3$ in both dians. intraocular pressure and CDR. $23 \%$ of subjects with an IOP $>21 \mathrm{mmHg}$ had a CDR greater than 0.5 , Fig. 3 and Table 5.

The same association was found when the mean mean IOP was found among persons with a large $>0.5)$ cup-disc ratio. These results are presented in Table 6.

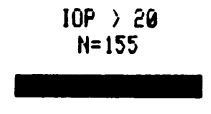




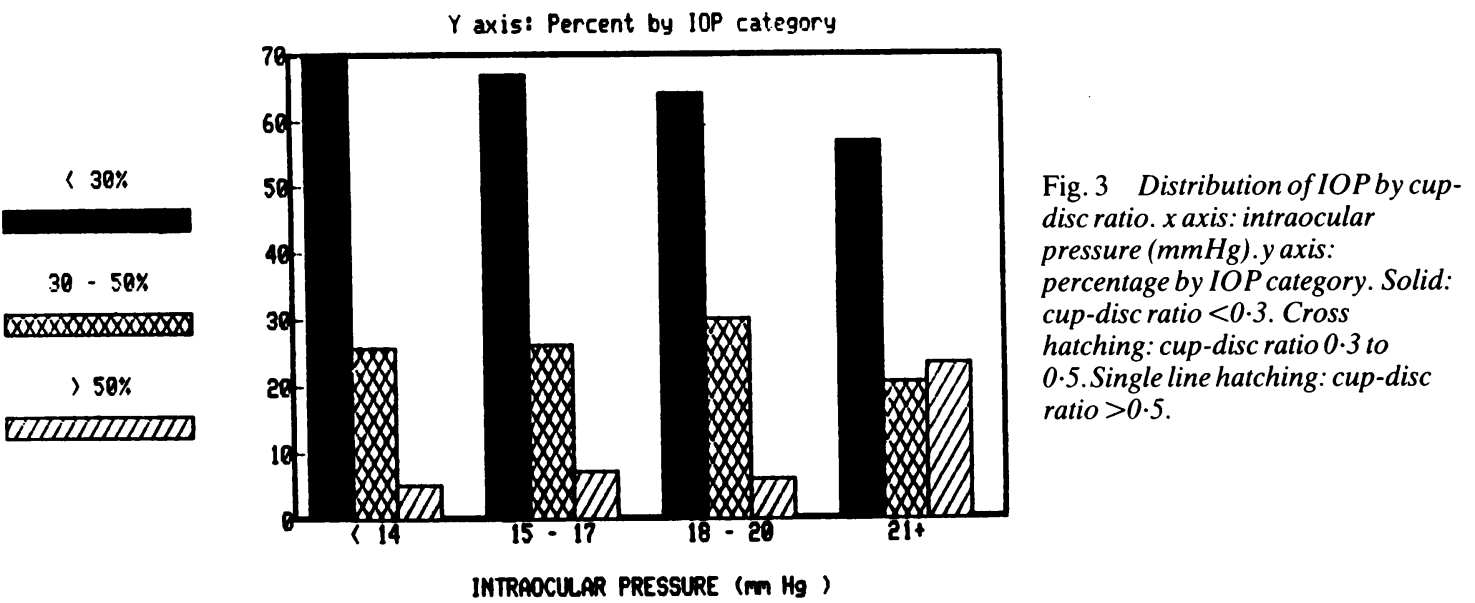

\section{INTRAOCULAR PRESSURE AND REFRACTIVE \\ STATUS}

The mean IOP was found to increase incrementally from a mean of $14.22 \mathrm{mmHg}$ in hypermetropes to $15.44 \mathrm{mmHg}$ in high myopes. This tendency was found to be statistically significant by analysis of variance $(p<0.001)$. This finding has been described in detail in a previous report.

\section{SYSTEMIC AND LIFE STYLE VARIABLES}

Age adjusted odds ratios (OR) and confidence limits (CI) were calculated for the association of raised intraocular pressure with the cardiovascular risk variables and other conditions by the MantelHaensztel pooled odds ratio across age strata and are presented in Table 7 . The odds ratio of a person having a raised IOP with a history of glaucoma in the family is over twice that of a person without a history of glaucoma in the family $(\mathrm{OR}=2.32,95 \% \mathrm{CI} 1.35$ to 4.00). The odds of a diabetic or a person with a sedentary life style having ocular hypertension were one and a half times that of a non-diabetic or active person $\mathrm{OR}=1.58$ and 1.41 respectively. Persons with cardiovascular disease or haemodynamic shock had lower odds of having ocular hypertension than persons without the condition, $\mathrm{OR}=0.51$ and 0.69 respectively. Systemic hypertension was not found to be associated with a raised intraocular pressure. It should be noted that all the confidence intervals, except for that of history of glaucoma in the family, included 1.

Analysis of variance was used to examine the relationship between mean IOP and other ocular, demographic, and medical conditions. Each variable that was associated with the dichotomous IOP variable (IOP $>20 \mathrm{mmHg}$ or $\mathrm{IOP}<21 \mathrm{mmHg}$ ) was entered into an analysis of variance test. Age, physical activity, diabetes, $\mathrm{CDR}$, and refractive
Table 5 Distribution of IOP bycup-disc ratio

\begin{tabular}{|c|c|c|c|c|c|c|c|c|}
\hline \multirow{3}{*}{$\begin{array}{l}I O P \\
(\mathrm{mmHg})\end{array}$} & \multicolumn{8}{|c|}{ Right cup-disc ratio } \\
\hline & \multicolumn{2}{|c|}{$<30 \%$} & \multicolumn{2}{|c|}{$30-50 \%$} & \multicolumn{2}{|c|}{$>50 \%$} & \multicolumn{2}{|l|}{ Total } \\
\hline & $n$ & $\%$ & $n$ & $\%$ & $n$ & $\%$ & $n$ & $\%$ \\
\hline$<14$ & 845 & $68 \cdot 6$ & 331 & $26 \cdot 9$ & 56 & $4 \cdot 5$ & 1232 & 100 \\
\hline $15-17$ & 463 & $66 \cdot 8$ & 185 & $26 \cdot 7$ & 45 & $6 \cdot 5$ & 693 & 100 \\
\hline $18-20$ & 267 & 66.9 & 109 & $27 \cdot 3$ & 23 & $5 \cdot 8$ & 399 & 100 \\
\hline $21+$ & 69 & $57 \cdot 5$ & 23 & $19 \cdot 2$ & 28 & $23 \cdot 3$ & 120 & 100 \\
\hline Total & 1644 & $67 \cdot 3$ & 648 & $26 \cdot 5$ & 152 & $6 \cdot 2$ & 2444 & 100 \\
\hline
\end{tabular}

Table 6 Mean IOP bycup-disc ratio (right eye)

\begin{tabular}{lllr}
\hline Cup-disc ratio & Mean IOP & $S D$ & $n$ \\
\hline$<0.3$ & 14.83 & $4 \cdot 02$ & 1632 \\
0.3 to 0.5 & 14.85 & 3.67 & 641 \\
$>0.5$ & 17.28 & $6 \cdot 70$ & 146 \\
\hline
\end{tabular}

Analysis of variance $\mathrm{F}=24 \cdot 00$, significance of $\mathrm{F}<0 \cdot 001$.

Table 7 Age adjusted percentage prevalence of raised IOP by condition

\begin{tabular}{|c|c|c|c|}
\hline \multirow[t]{2}{*}{ Condition } & \multicolumn{2}{|c|}{$\begin{array}{l}\text { Percentage of persons } \\
\text { with } I O P \geqslant 21 \mathrm{mmHg}\end{array}$} & \multirow{2}{*}{$\begin{array}{l}\text { Odds ratio } \\
\text { (95\% confidence } \\
\text { limits) } \\
\text { e }\end{array}$} \\
\hline & $\begin{array}{l}\text { Has } \\
\text { condition }\end{array}$ & $\begin{array}{l}\text { Does not have } \\
\text { condition }\end{array}$ & \\
\hline Hypertension $(n=2542)$ & $7 \cdot 2$ & $5 \cdot 8$ & $1.06(0.98-1 \cdot 15)$ \\
\hline Diabetes $(n=2543)$ & $10 \cdot 5$ & $5 \cdot 7$ & $1 \cdot 58(0 \cdot 81-3 \cdot 06)$ \\
\hline $\begin{array}{l}\text { Cardiovascular disease } \\
\quad(n=2538)\end{array}$ & $5 \cdot 0$ & $6 \cdot 3$ & $0.59(0.27-1.25)$ \\
\hline $\begin{array}{l}\text { Haemodynamic shock } \\
\qquad(n=2530)\end{array}$ & $4 \cdot 4$ & $6 \cdot 3$ & $0.69(0.36-1.32)$ \\
\hline $\begin{array}{l}\text { Lifelong sedentary life st } \\
\text { Sedentary versus } \\
\text { marked physical }\end{array}$ & tyle $(n=671$ & $5 \cdot 2$ & $1.41(0.57-3.47)$ \\
\hline $\begin{array}{l}\text { Glaucoma in family } \\
(n=2333)\end{array}$ & $11 \cdot 4$ & $5 \cdot 6$ & $2 \cdot 32(1 \cdot 35-4 \cdot 00)$ \\
\hline
\end{tabular}


Table 8 Analysis of variance: mean intraocular pressure of the right eye

\begin{tabular}{lrl}
\hline Independent variables & Fvalue & Significance of $F$ \\
\hline MAIN EFFECTS & & \\
Cup-disc ratio & $21 \cdot 19$ & $0 \cdot 001$ \\
Physical activity & $7 \cdot 54$ & $0 \cdot 001$ \\
Refractive status & $5 \cdot 82$ & $0 \cdot 001$ \\
Diabetes & $5 \cdot 23$ & $0 \cdot 021$ \\
Age (covariate) & 11.49 & $0 \cdot 001$ \\
\hline
\end{tabular}

$R^{2}=0 \cdot 044$.

status were each independently associated with a mean IOP after controlling for all dependent variables in both the right and left eye. These results are presented in Table 8. Family history of glaucoma was substituted for diabetes in an analysis of variance and found to be significant $(p=0.013)$ in the left eye, but not significant $(p=0.061)$ in the right eye. Systemic hypertension was not found to be independently associated with mean IOP in either eye $(p>0.05)$ when substituted for diabetes in the analysis. Twoway interactions were examined between each independent variable in each analysis. The only interactions that were found to be consistent in terms of statistical significance in both eyes were those between physical activity and refraction $(p<0.001)$ and refraction and diabetes $(p>0 \cdot 05)$. The amount of variance explained by the models was between 3 and $6 \%$.

\section{Discussion}

There have been several population based studies from which to estimate the prevalence of raised intraocular pressure. The prevalence estimates of this study, $6 \cdot 1 \%$ for $\mathrm{IOP} \geqslant 21 \mathrm{mmHg}$, compare well with other studies despite somewhat different methods of measurement in each study.

These estimates are based on 2594 persons or only $53 \%$ of the target study population. However, little difference was found between the age and sex distribution of respondents and non-respondents. It might be expected, however, that persons with eye problems or relatives with eye problems would be more likely to participate in the screening. The estimate of prevalence of raised intraocular pressure in the screened population might therefore be an overestimate of the prevalence in the general population. On the other hand, since persons over 70 years old are relatively underrepresented in the screened population, our estimate of the prevalence of elevated intraocular pressure is likely to be an underestimate of the prevalence in the general population.

The increase in mean IOP with increasing age, cup disc ratio, and myopia shown in our results also confirms evidence from other studies. ${ }^{67}$

Although the differences in IOP by age were statistically significant, the actual differences were small and therefore the clinical importance questionable.

It is not clear why persons born in Asia or Africa were found to have higher intraocular pressure than those born in Europe or America. The difference may be related to a darker iris pigmentation among persons from Asia or Africa. Several investigators have found that segments of the population, particularly blacks, tend to have a higher intraocular pressure than whites. ${ }^{3 \times 9110}$ Hiller et al. ${ }^{9}$ also found that iris pigmentation was associated with mean IOP, even after controlling for race. On the other hand Shiose and Kawase" have found that the distribution of IOP among the Japanese is generally lower than that of western societies. Since iris pigmentation was not assessed in this study, it is impossible to determine whether this or other factors are associated with the difference in mean intraocular pressure.

Positive associations between increased IOP and diabetes, glaucoma in the family, and systemic hypertension have been reported by others, ${ }^{+1012}$ some even showing an association between IOP and blood pressure. ${ }^{+1111}$

We found diabetes to be associated with the mean IOP but not with ocular hypertension, a possible reason for this being the somewhat arbitrary cut-off point of $21 \mathrm{mmHg}$ which defined ocular hypertension in this study.

Our study did not confirm the association between IOP and systemic hypertension previously reported. ${ }^{411}$ There might be two reasons for this. (1) We defined systemic hypertension based on the self-reported taking of antihypertensive medications and not based on a blood pressure measurement as other investigators; and (2) there was a relatively small number of persons with systemic hypertension and/or raised IOP. Therefore conclusions about the association between IOP and systemic hypertension based on this study would be tentative at best.

Refractive status has been shown to be associated with intraocular pressure ${ }^{73-15}$ and was therefore included in the analysis of variance.

There has been some discussion of the accuracy and reproducibility of test results obtained during screening for glaucoma. ${ }^{216-19}$ Interobserver variations in tonometry and optic disc assessment were evaluated on 103 respondents during this screening process and the results are published elsewhere. ${ }^{20}$

In conclusion, this study lends further support to the hypothesis that intraocular pressure is associated with age, country of birth (ethnic origin?), cup-disc ratio, refractive status, glaucoma in the family, and 
diabetes. However, there are probably many other as yet unidentified factors that contribute to the variation of mean IOP in a population as indicated by the small amount of variance attributed by the analysis of variance to the factors investigated in this study.

\section{References}

1 Cockburn DM. The prevalence of ocular hypertension in patients of an optometrist and the incidence of glaucoma occurring during long-term follow-up of ocular hypertensives. Am J Optom Physiol Opt 1982; 59: 330-7.

2 Leibowitz HM, Krueger DE, Maunder LR, et al. The Framingham eye study monograph. Surv Ophthalmol 1980; 24 (suppl): 335-610.

3 David R, Duval DON, Luntz, MH. The prevalence and management of glaucoma in an African population. $S$ Afr Arch Ophthalmol 1984; 10: 55-62.

4 Leske MC, Podgor MJ. Intraocular pressure, cardiovascular risk variables, and visual field defects. Am J Epidemiol 1983; 118: 280-7.

5 David R, Zangwill LM, Tessler Z, Yassur Y. The correlation between intraocular pressure and refractive status. Arch Ophthalmol 1985; 103: 1812-5.

6 Hollows FC, Grahm PA. Intraocular pressure, glaucoma, and glaucoma suspects in a defined population. Br J Ophthalmol 1966; 50: 570-86.

7 Seddon JM, Schwartz B, Flowerdew G. Case-control study of ocular hypertension. Arch Ophthalmol 1983; 101: 891-4.

8 Coulehan JG, Helzlsouer KJ, Rogers KD, Brown SI. Racial differences in intraocular tension and glaucoma surgery. Am J Epidemiol 1980; 111: 759-68.
9 Hiller R, Sperduto RD, Krueger DE. Race, iris pigmentation, and intraocular pressure. Am J Epidemiol 1982; 115: 674-83.

10 Klein BE, Klein R. Intraocular pressure and cardiovascular risk variables. Arch Ophthalmol 1981; 99: 837-9.

11 Shiose Y, Kawase Y. A new approach to stratified normal intraocular pressure in a general population. Am J Ophthalmol 1976; 101: 714-21.

12 Kahn HA, Leibowitz HM, Ganley JP, et al. . II. Association of ophthalmic pathology with single variables previously measured in the Framingham heart study. Am J Epidemiol 1977; 106: 33-41.

13 Tomlinson A, Phillips CI. Applanation tension and axial length of the eyeball. BrJ Ophthalmol 1970; 54: 548-53.

14 Perkins ES, Phelps CD. Open angle glaucoma, ocular hypertension, low-tension glaucoma, and refraction. Arch Ophthalmol 1982; 100: 1464-7.

15 Wallace J, Lovell HG. Glaucoma and intraocular pressure in Jamaica. Am J Ophthalmol 1969; 67: 93-100.

16 Moses RA, Lia OH. Repeated applanation tonometry. Am J Ophthalmol 1968; 66: 89-91.

17 Phelps CD, Phelps GK. Measurement of intra-ocular pressure: A study of its reproducibility. Graefes Arch Klin Exp Ophthalmol 1976; 198: 39-43.

18 Leydhecker W, Kriegelstein GK, Collani EV. Observer variation in applanation tonometry and estimation of the cup/disc ratio. In: Kriegelstein GK, Leydhecker W, eds. Glaucoma update. New York: Springer, 1979: 101-11.

19 Lichter PR. Variability of expert observers in evaluating the optic disc. Trans Am Ophthalmol Soc 1976; 84: 532-71.

20 Biedner B, Sachs U, David R. Interobserver variations in tonometry and optic disc assessment. Glaucoma 1983; 5: 160-3.

Accepted for publication 16 October 1986. 